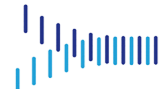 \\ PHPMA}

Published by

Department of Public Health and Preventive

Medicine, Faculty of Medicine,

Udayana University

\section{The impact of hospital accreditation on patient safety culture in the health services implementation at Sanglah General Hospital, Bali}

\author{
Putu May Indrayani, ${ }^{1 *}$ Pande Putu Januraga, ${ }^{2}$ Surya Negara ${ }^{3}$
}

'Polyclinic of Surgery, Sanglah General Hospital,

${ }^{2}$ Department of Public Health and Preventive Medicine, Faculty of Medicine, Udayana University, ${ }^{3}$ Department of Obstetrics and Gynecology, Faculty of Medicine, Udayana University/Sanglah General Hospital
*Correspondence to: Putu May Indrayani; Polyclinic of Surgery, Sanglah General Hospital; mayinrayani75@gmail.com

\section{ABSTRACT}

Background and purpose: Hospital accreditation is carried out to evaluate hospitals' performance in providing patients with excellent and safe health services. One aspect of service quality is patient safety culture. This study aims to determine the impact of hospital accreditation on patient safety culture in health service implementation at the Sanglah General Hospital in Denpasar City, Bali Province.

Methods: This study used a qualitative research design. In-depth interviews were conducted to 11 informants consisting of hospital management, clinicians and nurses which were chosen purposively since they were directly related to the assessment and supervision of health service providers at Sanglah Hospital. The interview guide was based on the Modified Manchester Patient Safety Framework (MaPSaF). Data were analyzed with a thematic approach.

Results: The interview results show that the ten dimensions of patient safety culture had been implemented well but still need to be improved in the dimensions of giving priority to safety, system errors and responsibilities, recording incidents and best practices, learning and influencing change, also education and training of staff and teamwork. The maturity level of patient safety culture at Sanglah Hospital is at generative culture in four dimensions and at proactive culture on the six dimensions of patient safety culture.

Conclusion: Accreditation had a positive impact on the maturity level of patient safety culture at a proactive level, mainly changes in knowledge, attitudes, and behavior in health service providers. However, in its implementation, there were still constrained on infrastructure, time, and energy.

Keywords: accreditation, patient safety culture dimension, patient safety culture maturity

Cite This Article: Indrayani, P.M., Januaraga, P.P., Negara, S. 2021. The impact of hospital accreditation on patient safety culture in the health services implementation at Sanglah General Hospital, Bali. Public Health and Preventive Medicine Archive 9(2): 108-115. DOI: 10.15562/phpma.v9i2.364

\section{INTRODUCTION}

Hospital accreditation is an effort to standardize the quality of hospital services by prioritizing patient safety as one of the essential outcomes of service delivery. ${ }^{1,2}$ The implementation of ongoing accreditation is needed to determine whether the application of patient safety standards has become a priority for a hospital. Thus, it indirectly aims to improve the culture of patient safety in service providers, service supporters, and hospital management. ${ }^{3}$

Patient safety culture is reflected by being competent in their field, perceptions, attitudes, behavior patterns that form the basis of commitment and skills in managing patient safety within the institution. ${ }^{4} \mathrm{~A}$ well-internalized patient safety culture will create a conducive, safe, and efficient work environment that satisfies hospital staff and employees and reflect to community complaints, suggestions, and criticisms. Also, it respects the patients' rights and obligations, involves patients themselves and their families in the treatment process, builds a culture of willingness to learn and to report every patient safety incident. Then, build hospital leaders' commitment by increasing cooperation and setting priorities to achieve sustainable patient quality and safety. ${ }^{5}$

The Sanglah Hospital was accredited by the the Joint Commission International
(JCI) and national accreditation with complete results. However, there are still problems in the behavior of stakeholders related to the implementation of patient safety culture such as hospital management support in patient safety, the overall perception of patient safety, staffing, nonblaming responses to the occurrence of errors and handoffs (handover). So far, the survey results have not received any follow-up and have not become the basis for determining policies at the leadership level, so that need to be explored related to patient safety culture at Sanglah Hospital.

One of the frameworks used to measure patient safety culture is the Manchester Patient Safety Framework (MaPSaF), 
which is then being utilized in a pilot project to assess patient safety culture in hospitals. ${ }^{6}$ This framework consists of ten dimensions of safety, including a commitment to continuous improvement, priority given to safety, system errors and individual responsibility, recording of incidents and best practices, evaluation of incidents and best practices, learning and influencing change, communication of patient safety issues, management and safety issues, staff education and training, and teamwork. Measurement of patient safety culture can be executed based on the dimensions underlying the maturity level of an organization in terms of implementing patient safety culture. ${ }^{7}$ The MaPSaF tools can help healthcare workers explore the level of development of organizational safety culture maturity, reflecting values, attitudes, and behaviors related to patient safety. ${ }^{89}$ Five patient safety culture maturity levels are pathological, reactive, bureaucratic, proactive and generative levels. ${ }^{6,8}$

This study aims to determine the effect of accreditation on the internalization of patient safety culture at Sanglah General Hospital under the MaPSaF.

\section{METHODS}

This study used a qualitative design with a case study approach. Informants were choosen purposively with the following criteria: had mastered research-related problems and had participated in the implementation of accreditation at Sanglah General Hospital. Interviews were held from June to July 2020 at Sanglah Hospital. A total of 11 informants have been successfully interviewed, who already reflected the elements of management, implementing medical services, nursing, and education. The selection of these informants was related to the supervision and assessment of patient safety culture carried out by health service providers in hospitals. Informants came from hospital management, medical specialist, heads of installations, nursing coordinators, heads of rooms, implementing nurses, and medical residency.

Data collection was carried out through in-depth interviews and report tracking. The interview guide consisted of topics from ten dimensions of patient safety culture developed from the MaPSaF and several questions the researcher developed related to the research objectives. While the search for reports was carried out on documents in the form of patient safety incident reports and patient safety culture reports, policies, guidelines, standard operational procedure (SOP) on patient safety which were used as evidence that supports the implementation of patient safety standards and to examine the conformity between existing regulations or documents related to safety patients at Sanglah Hospital.

Analysis of the data from in-depth interviews was carried out by thematic analysis. Itbegan with compiling transcripts of the results of the interviews, then giving a different code to each transcript to make it easier to classify the themes of each data obtained, mainly by listening to the results of interviews repeatedly to ensure that the interview results were transferred well into written form. The process was continued by coding, giving marks for essential words and related to the research concept. Next, the authors re-read the interview transcripts to group words that have the same meaning into several groups to be analyzed as themes as material in analyzing the impact of hospital accreditation on safety culture in health service providers at Sanglah General Hospital. All informants who were successfully interviewed received information related to research before the interview was conducted and signed their consent to participate on the informed consent form.

This research received ethical approval Number: 808/UN14.2.2.VII.14/LT/2020, dated April 17, 2020, from the Research Ethics Commission of the Faculty of Medicine, Udayana University/Sanglah General Hospital and Research Permit No: LB.02.01/XIV.2.2.1/20044/2020 from the President Director of Sanglah General Hospital.

\section{RESULTS}

The informants' characteristics can be seen in Table 1. We have balance male and female informants, while the age of the informants were ranged from 28 to 63 years old with length of working time varied from 2.5 to 30 years.

The results of in-depth interviews were mapped into ten dimensions of patient safety culture to analyze the cultural maturity. Table 2 is described sequentially

\section{Table 1. Characteristics of Research Informants}

\begin{tabular}{|c|c|c|c|c|c|}
\hline Code & $\begin{array}{l}\text { Age } \\
(y .0)\end{array}$ & Gender & Education & Work position & $\begin{array}{l}\text { Work } \\
\text { length } \\
\text { (years) }\end{array}$ \\
\hline $\mathrm{AR}$ & 31 & Male & $\begin{array}{l}\text { Bachelor degree in } \\
\text { nursing }\end{array}$ & Implementing nurse & 7 \\
\hline WD & 63 & Male & Medical specialist & Medical specialist & 20 \\
\hline TS & 54 & Female & $\begin{array}{l}\text { Bachelor degree in } \\
\text { nursing }\end{array}$ & Head of room & 27 \\
\hline KS & 47 & Male & $\begin{array}{l}\text { Bachelor degree in } \\
\text { nursing }\end{array}$ & Nursing coordinator & 23 \\
\hline $\mathrm{GH}$ & 53 & Female & Master in management & Head of nursing & 30 \\
\hline AS & 28 & Male & Medical specialist & $\begin{array}{l}\text { Head of emergency } \\
\text { installation }\end{array}$ & 12 \\
\hline $\mathrm{AN}$ & 53 & Female & Master in management & $\begin{array}{l}\text { Chair of the Quality } \\
\text { and Patient Safety } \\
\text { Committee }\end{array}$ & 30 \\
\hline $\mathrm{SD}$ & 60 & Male & Medical specialist & $\begin{array}{l}\text { Director of Medical and } \\
\text { Nursing }\end{array}$ & 30 \\
\hline $\mathrm{AK}$ & 56 & Male & Biomedicine Pharmacist & $\begin{array}{l}\text { Head of Pharmacy } \\
\text { Installation }\end{array}$ & 19 \\
\hline MW & 56 & Female & Medical profession & $\begin{array}{l}\text { Head of the Patient } \\
\text { Safety Sub Committee }\end{array}$ & 20 \\
\hline $\mathrm{CA}$ & 28 & Female & Medical profession & Surgical Resident & 2.5 \\
\hline
\end{tabular}


based on the cultural maturity level group of each dimension of patient safety culture. There are four dimensions which fall into generative maturity level, namely: commitment to continuous improvement, evaluate incidents and best practice, communication about patient safety issues, and management and safety issues. While, the other six dimensions fall into proactive maturity level.

Next, a narration of the interview results is presented that reflects the description of the cultural dimensions, the level of cultural maturity, and cultural change after hospital accreditation at Sanglah Hospital from various informants' statements which were successfully recorded in this study.

\section{Dimension 1: Commitment to continuous improvement}

In dimension 1, the maturity level of safety culture was at the generative level where investment in the quality of patient safety culture at Sanglah Hospital after hospital accreditation had been optimal. Those were mainly from infrastructure, human resources, information dissemination, training, patient safety rounds, the orientation of new employees, roadshows, and spreading questionnaires. Also, the formation of a patient safety team, seminars, workshops, policymaking, education, scientific activities and building commitments have been carried out continuously. The document search revealed that policies, guidelines, and SOPs on patient safety existed after international accreditation, the Joint Commission International (JCI), and updated every three years.

\section{Table 2. Analysis of cultural dimensions and maturity level of patient safety culture}

\begin{tabular}{lcl}
\hline $\begin{array}{c}\text { Dimensions of } \\
\text { patient safety } \\
\text { culture }\end{array}$ & $\begin{array}{c}\text { The maturity } \\
\text { level of } \\
\text { patient safety } \\
\text { culture }\end{array}$ & \multicolumn{1}{c}{ Reference classification on the maturity level of patient safety culture } \\
\hline $\begin{array}{l}\text { Commitment } \\
\text { to continuous } \\
\text { improvement }\end{array}$ & Generative & $\begin{array}{l}\text { Sanglah Hospital had invested in patient safety as optimally as possible from the provision of } \\
\text { infrastructure, human resources, and the dissemination process and commitment, which had } \\
\text { already been implemented according to patient safety standards. Collaboratively with all caregiving } \\
\text { professions. }\end{array}$ \\
\hline
\end{tabular}

Priority to safety Proactive

Implementation of patient safety culture at Sanglah Hospital still required control, continuity, and consistency. The reporting culture still needed to be improved. Patient safety had not fully become a culture; after accreditation, the staff became careless.

$\begin{array}{ll}\text { System error } & \text { Proactive } \\ \text { and individual } & \\ \text { responsibility } & \end{array}$

No Blaming Culture had not been fully implemented. In practice, there were still sanctions or warnings given by superiors to staff.

Reporting was not $100 \%$ yet. There were several obstacles, such as lack of understanding of incidents, lots of number of patients, not having time to write, or forgetting to report. While it mostly carried out by nurses, other professions had not reported enough. Feedbacks were still lacking.

\begin{tabular}{lll}
\hline $\begin{array}{l}\text { Recording incidents } \\
\text { and best practices }\end{array}$ & Proactive & $\begin{array}{l}\text { The Root Cause Analysis (RCA) team at Sanglah Hospital was still part-time. It had not entirely } \\
\text { focused on working on RCA and finding solutions related to patient safety incidents. }\end{array}$
\end{tabular}

Evaluate incidents and Generative
best practices
An investigation was carried out. The results were forwarded to the President Director and the Council for follow-up. Recommendations were made in guidelines, new SOPs, maintenance or facilities procurement according to accreditation standards. Patient safety reports were sent to the national level, where incidents could be prevented in other hospitals. The resulting data was used to evaluate patient safety systems and procedures, view incident trends, analyze improvements, and benchmark with other hospitals.

\begin{tabular}{|c|c|c|}
\hline $\begin{array}{l}\text { Learning and } \\
\text { influencing the } \\
\text { changes }\end{array}$ & Proactive & $\begin{array}{l}\text { The culture of having the courage to speak up, dare to remind, and the culture of being brave to } \\
\text { report by all staff had not been implemented well. Dissemination and evaluation of changes in } \\
\text { patient safety culture are needed, while, RCA did not reach the bottom line. }\end{array}$ \\
\hline $\begin{array}{l}\text { Communication about } \\
\text { patient safety issues }\end{array}$ & Generative & $\begin{array}{l}\text { Communication between staff, superiors and subordinates, and community to facilitate patient } \\
\text { safety culture had been carried out. However, nurses were always expected to remind doctors about } \\
\text { patient safety standards. }\end{array}$ \\
\hline $\begin{array}{l}\text { Management and } \\
\text { safety issues }\end{array}$ & Generative & $\begin{array}{l}\text { Simple investigation on an incident involving service staff was carried out by the immediate } \\
\text { supervisor. Sentinel incidents, followed by field investigations and interviews with staff, were } \\
\text { documented, which include examination of standards, staff competencies, and staff physical and } \\
\text { psychological assessments. Staff management was carried out by adding human resources and } \\
\text { setting work schedules. Staff was trained through orientation during staff recruitment which is } \\
\text { also maintained on the follow up. }\end{array}$ \\
\hline $\begin{array}{l}\text { Staff education and } \\
\text { training }\end{array}$ & Proactive & Not all staff had received patient safety training where the coverage of staff training was still $97 \%$ \\
\hline Teamwork & Proactive & $\begin{array}{l}\text { It had been effective. However, it was still necessary to supervise and evaluate team performance } \\
\text { because the duties of team members were still concurrent with functional tasks. }\end{array}$ \\
\hline
\end{tabular}




\begin{abstract}
"The investment we have made is an investment in infrastructure, then in human resources and the process. In our HR...preparing competent human resources following their competencies in each unit. For the process, for example, we also prepare materials that must be disseminated or educated, including SOPs, our educational materials have been included in Hospital IT so that all hospital communities can see what has to be done to implement this patient safety." (P10)
\end{abstract}

\section{Dimension 2: Priority is given to patient safety}

The level of cultural maturity in dimension 2 was still at the proactive level. The implementation of patient safety at Sanglah Hospital after accreditation, including reporting of incidents, the implementation of patient safety rounds carried out by management, training to improve HR competence, roadshows, implementation of patient safety culture were under standards, the results of the patient safety culture survey were getting better. However, patient safety had not become a culture, needed better control, continuity and consistency should be maintained at all times, and the reporting culture was needing improvement.

"In my opinion, the hospital staff need to payattention to maintain the consistency, continuity of the accreditation itself, because so far, usually after accreditation we are careless" (P8)

\section{Dimension 3: System error and individual responsibility}

The level of cultural maturity in this dimension was at the proactive level since the punishment for the staff mistakes and errors when a patient safety incident occurs should be in the form of no punishment. No Blaming Culture should be adopted, instead nurturing and encouraging feedback and recommendation should be implemented. After accreditation, there were still sanctions or warnings given by superiors which should be communicated in a better way

"As far as I know, it depends on the type of incident. If it is minor, it might be a warning or maybe explain the chronology of the incident. However, if it is major, as far as I know, there is a warning letter. There is a no blaming culture in the patient safety, so if we get punished or sanctioned, it will be a blaming culture. So there is still a blaming culture" (P1)

After the hospital accreditation, the system for reporting patient safety incident includes online and manual systems. It was mandatory for every staff who found incidents to report it through hospital information management system (SIMRS), however, only 50\% of the staff were reporting every month. The barriers to this reporting included unclear understanding of the incidents, high volume of patients, not having time to write or forgetting to report. Most of the reports were performed by nurses, whilst other professions had not reported much.

"It is not $100 \%$ entrenched yet, but it still has to be pushed again. The reason is we handle many patients, so do not have time to write. Well, reporting the incident can still be $2 \times 24$ hours for completeness of writing. There should still be someone's assigned to writing patient safety incidents." (P3)

"If I may be honest, for the reporting system, perhaps the only major progress is the nurses. So other professions are still lacking, including doctors, there are still very few of them who wants to report" (P5)

Incident reports were received and then analyzed monthly, then, reported every 3 months. The feedback was given to the reporting staff, followed by evaluation of systems and mechanisms in patient safety to improve standards, systems, and facilities as well as education and counseling to staff. However, the feedback to reported incidents were still poor including delayed response for the repairement needed.

"We have reported, for example, the problem of a broken ceiling... or other risks to other people. Sometimes the infrastructure needs to repair, but it may take a bit longer due to our bureaucracy. So, even we have reported it, then the follow-up of the report may need to be accelerated" (P4)

\section{Dimension 4: Recording incidents and best practices}

In this dimension, cultural maturity was still at a proactive level. After accreditation, every incident had been investigated by the immediate supervisor and the Patient Safety Sub Committee. However, the Root Cause Analyze (RCA) team at Sanglah Hospital was only working part-time, and the team also handle different tasks.

"Actually, in theory, the RCA team should be relieved from other tasks. It is just that only part of the time is used for RCA, part-time in our place. Because actually by being relieved of duties or thinking more about how to find the root of the problem and solutions, of course, more mature follow-ups will be carried out related to the RCA" (P7)

Every incident was reported through SIMRS; verification was executed and validated with grading. A sentinel event incident would be reported in $1 \times 24$ hours to the Patient Safety Team. The director immediately formed an investigation team to conduct RCA. The verification process and validation with grading had not been carried out $100 \%$. Documentation of the implementation of the verification, validation, or investigation process was quarterly and semesterly. The RCA reports related to sentinel incidents were already available and copied to the President Director and the Board of Directors.

"The implementation is not yet 100\% implemented. There is the Head of the Room who verifies and validates. Nevertheless, for the time being, there is a culture to just report. Later, the patient safety team will review whether the verification or the validation is still lacking. It has only been reported, and for verification, there are several already implemented" (P3)

\section{Dimension 5: Evaluating incidents and best practices}

The cultural maturity level on this dimension was at the generative level. After accreditation, each incident was evaluated by conducting an investigation. The results were forwarded to the President Director and Board of Directors for follow-up and recommendations. The results of an investigation of a patient safety incident 
were in the form of adapted guidelines, new SOPs, and repairs or procurement of facilities under accreditation standards. Improvements through the Plan Do Study Act (PDSA) approach for improvements to systems, procedures, flow, human resources were able to attain based on the results of patient safety analysis.

"Already, the patient safety incident was reported, which has been recorded, even if a serious incident such as a sentinel occurs, the president director will know within 24 hours, and we will report it to the supervisory board. After that, the President Director will provide recommendations, and we must implement them so that the same mistakes do not occur" (P8)

Regarding patient safety, recognition of best practices after accreditation had been widely carried out at Sanglah Hospital as a lesson for staff, management, and other hospitals. Many innovations about patient safety had been implemented, such as reporting critical results through IT, such as the time out by chemo patients, and had received an award from Indonesian Hospital Association (PERSI).

\section{Dimension 6: Learning and influencing change}

In this dimension, Sanglah Hospital was still at a proactive level. The mechanism used to learn from the incident was to increase the culture of having the courage to speak up, dare to remind, and be brave to report to all staff, but this had not been appropriately implemented. After a new policy, the information dissemination and evaluation were carried out, then the results disseminated to staff through training and quarterly/semester meetings. However, sometimes the results of RCA did not reach the bottom line.

"Yes, we were talking about culture a long time ago, yes, but what we develop, echo, and applaud at this Hospital is brave to speak culture. The culture to be brave to remind and brave to report that is what we have to do. Really support our entire staff and do not forget no blaming culture" (P7)

"it does not reach, ma'am. RCA is done at the installation. Sometimes RCA results do not reach the bottom line."

\section{Dimension 7: Communication about patient safety issues}

The level of cultural maturity in this dimension of Sanglah Hospital was at the generative level. The communication system in developing a patient safety culture after hospital accreditation was conducted through SIMRS, regular meetings on quality and patient safety, and dissemination of SOPs. Also, it was amplified through leaflets, posters about patient safety, direct checking by supervisors, monitoring staff, and communicating directly with patients. It can be conducted by communication between staff, superiors and subordinates, and community communication to facilitate a patient safety culture. However, sometime nurses were expected to remind doctors about patient safety standards.

"The first communication system is from training, and the second is maybe the nurse who is appointed as the spearhead to always reminds each other as well as doctors or residents to continue to comply with patient safety operational standards" (P11)

"This hospital SIM is good enough. It is just our compliance to input data every time there is an incident. Maybe this is needed to be optimized" (P4)

\section{Dimension 8: Management and safety issues}

This dimension already reflected the level of a generative culture where security issues after hospital accreditation were managed well in practice. Simple investigation was conducted for incidents that involving service staff by the direct supervisor. Followed by evaluation of the standards and competencies of staff, then conducted an assessment of the physical and psychological of the staff and also supporting infrastructures.

"When there is an incident involving the implementing staff, as I said, we do not blame the implementing staff. We handle the incident first, whether it is with physical treatment, such as psychological. Then a problem analysis is carried out, either through a simple investigation or through RCA, according to the grading results" (P7)
Staff management issues, recruitment, and selection of safety procedures followed the processes and efforts to maintain patient safety in staff reception. The nursing rounds, management rounds, and patient safety rounds were carried out more routinely. Staffs were trained through orientation during staff reception which is mandatory training for all employees at Sanglah Hospital. It is also maintained through morning briefing, information dissemination and refresher courses. The Patient Safety Sub-Committee had prepared reports on the implementation of the patient safety round by management.

"So, each new staff will be taught lessons such as information dissemination, including training during orientation, every year there will also be re-education on patient safety. Including students, all employees are required to complete online training" (P4)

\section{Dimension 9: Staff education and training}

In this dimension, Sanglah Hospital was still at the level of proactive culture. Hospital accreditation had a good impact on the patient safety training program for staff, which had begun to be implemented through E-Learning at Hospital Management Information System, workshops, and seminars on patient safety, including medication safety. A report on implementing patient safety training already existed and was prepared by the Education and Training Section of Sanglah Hospital. However, not all staff had received patient safety training where the coverage of staff training was still $97 \%$.

"Not all staff have received patient safety training; the coverage of staff training is still 97\%"(P5)

\section{Dimension 10: Teamwork}

For the $10^{\text {th }}$ dimension, teamwork, was still at the level of proactive culture. After accreditation, a safety team was developed at the Hospital, which is a patient Safety Sub-Committee as part of the Patient Quality and Safety Committee as outlined on the Decree on the Determination of the Patient Safety Team by the Hospital President Director. The number of team that work to handle patient safety issues consisted of 19 people: chairperson, 
secretary and patient safety person in charge, but in practice, it had not been effective since the duties of team members were still concurrent with other functional tasks, so it was necessary to supervise and evaluate the team performance.

"Under the quality and patient safety committee, one of the sub-committees is the patient safety sub-committee. This patient safety sub-committee has a secretary, and then some PICs work in all work units that carry out data input activities, monitoring and making data reports related to patient safety" (P10)

"So the effectiveness is relative. Because there is no special person, so all this time, all are part-time. So most of these safety patients are concurrently functional as usual. Then, to carry out investigations, more intensive information dissemination may be constrained. Because they will also carry out their functional duties as staff" (P4)

\section{Impact of patient safety culture after accreditation at Sanglah Hospital}

Changes in patient safety culture at Sanglah Hospital after accreditation increased knowledge, changed attitudes and behavior, although sometimes the continuity of the implementation of patient safety culture was still constrained by infrastructure, time and energy. The informants highlighted the most significant change in patient safety culture was the culture of handwashing.

"Clearly, all of us have changed, from those who were ignorant, then all of us have better knowledge, behavior, and attitudes.... There are still obstacles in our provision of facilities and infrastructure. At certain points, we can even lack hand rub, although, in certain places, there must be. Anyhow, sometimes we are still a bit lacking in that" (P6)

"Significant changes, yes, a lot. Especially the most significant is that person's habit of washing their hands, including everyone in the Hospital. In particular, the doctors, nurses, medical students, nursing students, has a very, very significant effect" (P8).

\section{DISCUSSION}

From the analysis of the dimensions of patient safety culture in this study, Sanglah Hospital was at the maturity level of a generative culture in four dimensions: the dimensions of commitment to continuous improvement, evaluation of incidents and best practices, communication about patient safety issues, and management and safety issues. The maturity level of proactive culture were found in the other six dimensions: the dimensions of priority given to safety, system errors and individual responsibility, recording incidents and best practices, learning and influencing change, staff education and training, and teamwork dimensions.

The maturity level of a generative culture reflect the organization continuously learns from failures and successes and then evaluates interventions' effectiveness. Information search is carried out actively, and accountability is shared, whistle blowers are trained, new ideas are accepted, causes of failure are investigated, and coordination is rewarded. Patient safety is always prioritized in providing optimal service, and this must be instilled in everyone's heart and mind. The maturity level of a proactive culture where the organization aims to achieve high scores in improving patient safety is reflected in the investment made in the continuous improvement of patient safety. This system is comprehensive, involves stakeholders, broad-scale, and an evidence-based approach has been established in the organization. ${ }^{8,6}$

Sanglah Hospital was at the maturity level of a generative culture for some dimensions after accreditation that showed adequate investment, positive commitment and proper evaluation of the implementation. Meanwhile, the discovery of innovations regarding patient safety continues to be carried out at Sanglah Hospital or even implemented in other hospitals. A safety culture assessment begins with developing a patient safety program to identify areas/units to be developed. Program evaluation is used to make comparisons internally and externally and as a basis for policymaking. ${ }^{10,11}$
After accreditation, the communication system at Sanglah Hospital was established to improve patient safety culture at the hospital, mainly through SIMRS, quality meetings to convey patient safety issues to staff, dissemination of SOPs, leaflets, and posters about patient safety. Direct communication to staff and patients should be carried out regularly to increase staff motivation in implementing patient safety culture. The nursing procedures have undergone many changes that have contributed to professionalism and opportunities for learning. ${ }^{12}$

Sanglah Hospital was still at the maturity level of a proactive culture for six of the ten dimensions, hence, better control, continuity and consistency in reporting culture must be improved. The adoption of patient safety to become a culture is a major factor in the success of patient safety programs, and one of the critical factors is the commitment of all stakeholders to carry out patient safety according to standards. All hospital components must change the culture by implementing patient safety principles in daily service activities. ${ }^{13}$ When a patient safety incident occurs, punishment for staff misconduct should not include a blame culture. ${ }^{14}$ Feedback affects individual performance through attitude and ability variables, ${ }^{15}$ while patient safety incident reporting is designed to obtain information about patient safety that can be used in individual and organizational learning processes. ${ }^{10}$

After accreditation, the culture of having the courage to speak up, having the courage to remind, and report to all staff had not been entrenched, so it continues to be promoted and prioritized in the patient safety program at Sanglah Hospital. Information dissemination needs to be improved by conducting regular monitoring and evaluation to ensure that the analysis results of all incidents reach the bottom line. A health organization will have a positive patient safety culture if it has cultural dimensions such as: an open culture, a just culture, a reporting culture, a learning culture, and an informed culture. ${ }^{10}$ Not all staff have received patient safety training where the scope of staff training was still $97 \%$, so 
the hospital continues to carry out patient safety education and training face-to-face or online and as mandatory training for all staff. Training is the dominant factor in influencing the reporting of patient safety incidents. ${ }^{15}$

Meanwhile, the performance of the Patient Safety Team was still not effective because the duties of team members were still concurrent with other functional tasks which may constrain them in carrying out their duties, so supervision and evaluation of team performance must still be carried out. The Decree for the Formation of the Patient Safety Team already exists and is determined by the President Director of Sanglah Hospital. According to Jenita et al., 2019, the patient safety team needs to be considered in reporting patient safety incidents and the team must hold regular incident reporting surveys to the head of the room..$^{15}$

\section{Impact of Hospital Accreditation}

The accreditation has a positive impact on the maturity level of patient safety culture at Sanglah Hospital. It had an impact on changes in knowledge, attitudes, and behavior of health service providers. The most significant impact of patient safety culture was reporting culture, hospital cleanliness, staff knowledge in implementing patient safety standards, and handwashing culture. However, implementing a patient safety culture was still constrained by facilities, time, and energy.

Efforts were needed to increase the maturity level of patient safety culture from all staff and employees at Sanglah Hospital to be more consistent in implementing patient safety standards to increase cultural maturity to the generative maturity level on all dimensions of patient safety culture. Improving the implementation of the ten dimensions of patient safety requires encouragement, a shared commitment to improve continuity and consistency, and the provision of infrastructure, such as the availability of medical and non-medical goods, facilities according to patient safety standards, and adequate human resources, including a team that can carry out particular tasks in monitoring, evaluating, and patient safety education. To attain optimal safety culture at Sanglah Hospital, clinicians should always pay attention to accreditation standards related to patient care, clinical practice guidelines, clinical pathways, and SOPs regarding patient safety. Compliance to those guidelines should be used as a necessity and awareness to prioritize patient safety. Moreover, the implementation of patient safety standards can be used as one of the performance indicators for the hospital employees.

\section{Study limitation}

The researcher's experience as a staff member at Sanglah Hospital, where the participants of this study were the hospital management: the Director of Medical, Nursing, and Support Services, caused the researchers to feel a gap that influence rapport with the participants. Another constraint was the researcher's status as the room's leader in this hospital; some of the participants were implementing nurses that somehow may feel embarrassed and affect their responses.. The time of data collection which collided with the COVID-19 pandemic, causing difficulty in agreeing to conduct interviews due to the participants' respective schedules.

\section{CONCLUSION}

The ten dimensions of patient safety culture from the Modified Manchester Patient Safety Framework (MaPSaF) at Sanglah Hospital had been implemented well but still need to be improved in several dimensions. The maturity level of patient safety culture was at generative culture on four dimensions and proactive culture on six dimensions. Accreditation at Sanglah Hospital, in general, had a positive impact on the maturity level of patient safety culture including changes in knowledge, attitudes, and behavior in health service providers, but in its implementation, there were still constraints in infrastructure, time, and energy. There are improvements that should be made for each dimension to optimally implement the patient safety culture.

\section{ACKNOWLEDGMENT}

The author would like to thank the President Director of Sanglah Hospital Denpasar, management, specialist doctors, students, head of the room, and implementing nurses who have given permission and assistance to the authors in conducting this research.

\section{AUTHOR CONTRIBUTION}

MI arranged the research, collected, analyzed the data, and composed the first draft of the manuscript of this research. PJ and SN provided input on research concepts and designs, analyzed data, and edited the manuscript.

\section{CONFLICT OF INTEREST}

The authors declare there is no conflict of interest.

\section{FUNDING}

The authors entirely funded the research.

\section{REFERENCES}

1. Mandawati M, Fu'adi MJ, Jaelan J. Impact of hospital accreditation: qualitative study to nurses in RSUD KRT Setjonegoro of Wonosobo. Nurscope. 2018; 4(1): 23-29.

2. Morello RT, Lowthian JA, Barker AL, McGinnes R, Dunt D, Brand C. Strategies for improving patient safety culture in hospitals: a systematic review. BMJ Quality \& Safety. 2013; 22(1): 1118.

3. Wardalia N, Dewi A. Peran akreditasi klinik dalam implementasi budaya keselamatan pasien di Klinik Firdaus Yogyakarta [The role of clinic accreditation in implementation of patient safety culture in Firdaus Clinic Yogyakarta] [Thesis]. Muhammadiyah Yogyakarta University. 2018.

4. Hodgen A, Ellis L, Churruca K, Bierbaum M. Safety culture assessment in health care: a review of the literature on safety culture assessment modes. Australian Commission on Safety and Quality in Health Care [Internet]. 2017. 1-65. Available from: https://www.safetyandquality. gov.au/wp-content/uploads/2017/10/SafetyCulture-Assessment-in-Health-Care-A-reviewof-the-literature-on-safety-culture-assessmentmodes.pdf

5. Kusbaryanto. Peningkatan mutu rumah sakit dengan akreditasi [Increasing hospital quality by accreditation]. Mutiara Med. 2010; 10(1): 86-89.

6. Astika A. Assessing patient safety culture in the hospital: a pilot study using a Modified Manchester Patient Safety Framework (MaPSaF). J Medicoeticolegal dan Manaj Rumah Sakit. 2017; 6(3): 159-168.

7. Wallis K, Dovey S. Assessing patient safety culture in New Zealand primary care: a pilot study using a modified Manchester Patient Safety Framework in Dunedin general practices. J Prim Health Care. 2011; 3(1): 35-40. 
8. Parker D, Lawrie M, Hudson P. A framework for understanding the development of organisational safety culture. Saf Sci. 2006; 44(6): 551-562.

9. Davis H. The Royal Wolverhampton Hospitals: Trust Board Report. NHS Trust [Internet]. 2011. Available from: https:// www.royalwolverhampton.nhs.uk/about-us/ trust-board-meetings-2022/2011-trust-boardpapers/

10. Stavropoulou C, Doherty C, Tosey P. How effective are incident-reporting systems for improving patient safety? a systematic literature review. Milbank Q. 2015; 93(4): 826-866.

11. Agustina D. Safety culture assessment: a tool for improving patient safety in hospital. $J$
Medicoeticolegal dan Manaj Rumah Sakit. 2018; 7(2): 127-135.

12. Rajasoorya C. Clinical ward rounds-challenges and opportunities. Ann Acad Med Singap. 2016; 45(4): 152-156.

13. Iskandar $H$, Maksum $H$, Nafisah N. Faktor penyebab penurunan pelaporan insiden keselamatan pasien rumah sakit [Factors influencing the decrease in hospital patient safety incident reporting]. J Kedokt Brawijaya. 2014; 28(1): 72-77.

14. Yasmi Y, Thabrany H. Faktor-faktor yang berhubungan dengan budaya keselamatan pasien di Rumah Sakit Karya Bhakti Pratiwi Bogor Tahun 2015 [Factors associated with patient safety culture in Karya Bhakti Pratiwi
Bogor Hospital 2015]. J Administasi Rumah Sakit. 2018; 4(2): 98-109.

15. Jenita A, Arief YS, Misbahatul E. Analisis faktor yang berhubungan dengan pelaporan insiden keselamatan pasien pada perawat [Analysis of factors related to the reporting of patient safety incidents among nurses]. Fundam Manag. 2019; 2(1): 7-15.

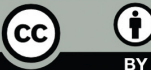

This work is licensed under a Creative Commons Attribution 